\title{
Perspectivas de região e redes na política de saúde brasileira
}

\author{
Prospects for the region and networks in Brazilian health policy \\ Mariana Vercesi de Albuquerque ${ }^{\mathbf{1}}$, Ana Luiza d'Ávila Viana²
}

RESUMO Regiões e Redes de Atenção à Saúde são estratégias recentes da política de saúde brasileira. Questiona-se: quais concepções de região e redes de saúde informam a política, como se combinam, em que momentos e com quais objetivos? Analisaram-se as perspectivas de região e redes adotadas na política de saúde, no período de 2001 a 2011 . Utilizou-se o referencial da geografia humana (geografia crítica) e da análise de políticas públicas (institucionalismo histórico), pesquisa bibliográfica, documental e dados secundários. Identificaram-se três fases de indução descompassada dessas estratégias, orientadas por distintas concepções teóricas e políticas e interesses nacionais e internacionais.

PALAVRAS-CHAVE Regionalização; Política de saúde; Sistema Único de Saúde; Planejamento em saúde; Assistência à saúde.

\begin{abstract}
Regions and health care networks are strategies recently adopted in the Brazilian health policy. Leading questions: what conceptions of region and health networks inform the policy, how are they combined, at what times and with what objectives? The aim of this study is to analyze the prospects for the region and networks adopted in health policy in the period of 20012011. We used the reference of human geography (critical geography) and public policies analysis (historical institutionalism), bibliographic research, documentary research and secondary data. Were defined three induction phases apart from these strategies, guided by different theoretical and political views and national and international interests.
\end{abstract}

KEYWORDS Regional health planning; Health policy; Unified Health System; Health planning; Delivery of health care.

1 Fundação Oswaldo Cruz (Fiocruz), Escola Nacional de Saúde Pública Sergio Arouca (Ensp), Departamento de Administração e Planejamento em Saúde (Daps) - Rio de Janeiro (RJ), Brasil. mariana.albuquerque@ensp. fiocruz.br 


\section{Introdução}

A adoção de práticas de planejamento regional (em uma perspectiva geral), através da institucionalização de regiões e/ou elaboração de projetos vinculados às regiões geográficas específicas, caracterizou um papel estratégico assumido pelo Estado na condução do desenvolvimento econômico e social em diversos países, na primeira metade do século XX.

O planejamento regional perdeu força a partir da década de 1970, no contexto da emergência da agenda neoliberal, com proposta de reformas do Estado, e no processo de globalização econômica, com novos paradigmas tecnológicos e expansão da atuação de instituições e empresas em escala planetária. O planejamento regional tornou-se limitado principalmente por forças e interesses de grupos privados, com autonomia de mobilização de recursos diversos, cuja estratégia de atuação é constituir redes em diferentes escalas regionais, nacionais e internacionais e influenciar políticas nos distintos lugares e regiões onde se estabelecem.

As perspectivas da descentralização político-administrativa e do planejamento local (pautado pela relação local-global), associadas às tendências de privatização de serviços públicos, tiveram destaque nas agendas internacionais e governamentais. A conformação de redes globais de produção, serviços, informação e logística para viabilizar a atuação das instituições de mercado passou orientar o planejamento territorial, com investimentos nas regiões mais competitivas e conectadas por meio dessas redes (CASTILLO, 2008).

Nos anos 2000, limites e conflitos decorrentes do aumento das desigualdades e da competitividade entre regiões e países recolocou na agenda internacional o debate sobre o papel do Estado na condução do planejamento territorial. Entre as principais questões que orientaram esse debate, estão: (I) a participação de representantes do mercado e da sociedade; (II) a visão integrada dos usos do território e das redes, não restrito a determinado setor da administração pública ou da economia; (III) a relação de planos nacionais com blocos regionais (ex: União Europeia); (IV) o combate às desigualdades socioespaciais, valorização das potencialidades econômicas ligadas ao mercado interno e externo e melhoria de acesso e qualidade de serviços públicos; (V) a percepção das várias escalas (local, regional, nacional e internacional) de atuação técnica e política dos diversos agentes e instituições, para a estruturação e negociação de planos regionais e a regulação das redes financeiras, de serviços, produção, informação e logística; (VI) a ideia de sustentabilidade associada aos padrões de crescimento econômico, utilização dos recursos físicos e tecnológicos e promoção do bem-estar social ${ }^{1}$ (SANTOS; SILVEIRA, 2001).

No Brasil, nos anos 2000, a retomada do papel do Estado na condução do planejamento territorial se pautou pelo debate contemporâneo e se traduziu na elaboração de políticas regionais implícitas e explícitas ${ }^{2}$, além do incentivo de processos de regionalização, inclusive na política de saúde.

Nesse contexto, a conformação de regiões e redes de saúde se tornaram estratégias da política nacional para lidar com a dimensão territorial da universalização da saúde e induzir mudanças na política, no planejamento e gestão do Sistema Único de Saúde (SUS), a fim de assegurar uma ação mais eficaz do Estado na garantia desse direito (ALBUQUERQUE, 2013).

Questiona-se: quais concepções de região e redes foram estabelecidas no âmbito da política nacional de saúde, como se combinaram, em que momentos e com quais objetivos?

O objetivo do trabalho foi analisar as perspectivas de região e redes adotadas na política de saúde brasileira, no período de 2001 a 2011.

\section{Metodologia}

Utilizou-se o referencial teórico da geografia humana (geografia crítica) e da análise de políticas públicas (institucionalismo histórico),
1 Palestra proferida no Instituto de Economia da Universidade Estadual de Campinas (Unicamp) em 30/05/2012, por Tania Bacelar de Araújo. Título: Desenvolvimento Regional no Brasil.

2 Idem 
pesquisa bibliográfica, análise documental e de dados secundários. Realizou-se revisão bibliográfica sobre região geográfica, planejamento regional e redes, para compreensão de seus significados para além do setor saúde. Identificaram-se as principais experiências e definições teóricas que influenciaram a política de saúde brasileira. Definiram-se fases da indução da regionalização e da conformação de redes segundo as normas e concepções utilizadas na política nacional, entre 2001 e 2011.

\section{Principais concepções de região e redes que influenciaram a política de saúde brasileira, pós-1988}

A organização de regiões de saúde e redes assistenciais estão previstas na Constituição Federal (1988) e na Lei Orgânica da Saúde (8.080/1990). Seguindo as regras constitucionais e o modelo federativo do País, uma região de planejamento é um recorte instituído pelo Estado (esferas federal e estadual), em um dado momento, subordinado a uma política específica, com critérios, objetivos e recursos predefinidos.

Esse tipo de planejamento não cria um novo ente político com orçamento próprio, depende da capacidade, autonomia e solidariedade das três esferas de governo para: elaborar uma visão estratégia sobre os usos do território, suas redes e especificidades regionais; propor um plano regional de médio e longo prazo, com objetivos e metas claros; planejar, financiar, mapear e regular redes de produção, serviços, logística e informação; negociar e coordenar ações com diferentes setores, agentes, instituições e esferas de governos com atuação na região de planejamento e em outras escalas - local, regional, nacional e internacional.

Tanto as regiões geográficas como aquelas instituídas para fins de planejamento se estruturam por meio de redes técnicas e políticas. Não existem regiões sem redes. Estas integram e coordenam fixos e fluxos (produção, informação, circulação e consumo) entre diferentes lugares, inserindo-os dentro de uma mesma lógica produtiva, configurando uma solidariedade regional (SANTOS; SILVEIRA, 2001). As redes criam e recriam arranjos técnicos e institucionais, combinando diferentes escalas de ação e poder econômico e político que escapam aos limites regionais, tornando mais complexas as interações regionais. Nesse sentido, a região geográfica é um recorte dinâmico que exprime bases de ação técnica e política que não necessariamente coincidem com o desenho regional do planejamento (SILVEIRA, 2010).

As regiões de planejamento do SUS sempre foram pensadas em combinação a conformação de redes. Portanto, as perspectivas de regionalização são condicionadas pelo entendimento sobre rede de saúde. Duas principais perspectivas de rede influenciaram as diretrizes de regionalização do SUS: (I) redes regionalizadas e hierarquizadas, de origem inglesa; e (II) Redes de Atenção à Saúde (RAS), inspirada no conceito de sistemas integrados de saúde, de origem norte-americana.

Anteriormente às propostas de regionalização, mas também influente nessa perspectiva, o modelo norte-americano de Centros de Saúde (CS), difundido pela Fundação Rockfeller, no início do século XX, deixou marcas na organização do SUS até recentemente, através da ideia de integração das ações assistenciais, sendo contraposto atualmente pelos novos componentes gerenciais das RAS (MELLO ET AL., 2011). Destaca-se ainda que as noções de territorialidade (comunidade e desigualdades locais/intraurbanas) e de territorialização (estruturação de sistemas e redes municipais de saúde) foram muito valorizadas durante a descentralização, envolvendo distritos sanitários e atenção primária em diferentes situações sociais e de saúde, sendo posteriormente, e em parte, atualizadas e ampliadas para o contexto regional de planejamento do SUS.

No processo de indução da regionalização, a política brasileira foi primeiramente muito influenciada pela proposta das redes assistenciais regionalizadas e hierarquizadas para sistemas universais de saúde, inspirada no Relatório Dawson, de 1920. Os serviços 
médicos eram ordenados em redes, com centros de saúde primários, secundários e hospitais de ensino e a abrangência regional de acesso a eles. Para garantia de acesso ao cuidado integral, a regionalização deveria ser baseada em territórios de grande porte populacional, com autossuficiência em recursos de saúde em todos os níveis de atenção, subdivididos em distritos, sub-regiões ou microrregiões. Tratava-se de uma divisão técnica, gerencial e territorial do trabalho no setor saúde, que relacionava hierarquia dos serviços (especialidade do tratamento; variedade de equipamentos e profissionais), com hierarquia urbana (porte populacional; equipamentos e serviços; função rural ou urbana) e redes de transporte e comunicação, criando uma organização regional de um sistema de saúde, conforme a complexidade e a complementaridade dos serviços oferecidos. A rede regionalizada e hierarquizada estaria sob o comando da autoridade única de saúde regional, de cunho administrativo.

Alguns dos conceitos foram incorporados na política brasileira, tais como: critérios de delimitação regional baseado na oferta, fluxo e hierarquia assistencial e nas necessidades de saúde de uma comunidade; a eficiência de escala; a coordenação das referências de acesso entre os níveis e/ou regiões. Contudo, a criação da autoridade de saúde única na região, instrumento fundamental da proposta, não se aplicou ao caso brasileiro, dado o modelo federativo de corte municipalista, cujo processo de descentralização dificulta a constituição desse tipo de autoridade.

Essa questão representou uma importante limitação para a indução e institucionalização da regionalização do SUS. Outras três questões também precisavam ser mais bem compreendidas e definidas dentro do planejamento regional do SUS: (I) o conceito de rede de saúde (MENDES, 2010); (II) a consideração das desigualdades socioespaciais; (III) e as relações estabelecidas entre Estado e mercado na configuração de redes assistenciais com lógicas próprias, sob forte comando do setor privado, a despeito do processo de regionalização (IBAÑEZ ET AL., 2009; SCATENA ET AL., 2014).

A noção de redes hierarquizadas e regionalizadas foi perdendo espaço para outra perspectiva, das RAS. A noção de redes de atenção que passou a informar a política de saúde brasileira tem origem no conceito de sistemas integrados de saúde, desenvolvido para o mercado privado americano e adaptado para as políticas públicas e sistemas universais de saúde (MENDES, 2010; KUSCHNIR; CHORNY, 2010).

$\mathrm{Na}$ década de 1990, houve um esforço por parte da Organização Mundial da Saúde (OMS) para a formulação de um conceito sofisticado de rede de saúde, baseado em sistemas integrados, capaz de embasar e alinhar o planejamento de sistemas universais de saúde em tempos de globalização, relacionado à difusão dos ideais da nova gestão pública, de boa governança e da reforma desses sistemas (MENDES, 2014), também à proposição de um 'novo universalismo' (WHO, 2000).

Os modelos de gestão de sistemas integrados de saúde foram introduzidos em países da Europa e no Canadá, no contexto das reformas dos sistemas de saúde, nos anos $90 . \mathrm{Na}$ mesma época, esses modelos começaram a ser adaptados na América Latina e, nos anos 2000, difundiram-se em alguns países, entre eles o Brasil (WHO, 2000; OPAS, 2010). Experiências latino-americanas tomam como principal exemplo o sistema integrado de saúde da Catalunha, Espanha (OPAS, 2010). Desde então, a OMS tem conseguido criar um consenso internacional em torno da necessidade de conformação das redes e sistemas integrados de saúde nos sistemas nacionais.

No Brasil, o conceito adaptado por Mendes (2010, P. 2300) tem forte influência na política nacional. Segundo o autor, as RAS são "organizações poliárquicas de conjuntos de serviços de saúde [...] coordenadas pela atenção primária à saúde". Os elementos constituintes das redes são: a população pela qual a rede se responsabiliza; a estrutura operacional e o modelo de atenção. As redes se integram por linhas de 
cuidado, que servem como diretrizes para a estratégia de articulação e gerenciamento das unidades e dos atendimentos na rede.

A noção de integralidade aparece relacionada às redes, sugerindo dupla leitura: redes como estrutura organizacional de produção de serviços e redes como dinâmica de atores e organizações em permanente negociação (HARTZ; CONTANDRIOPOULOS, 2004). Do ponto de vista da coordenação política, as RAS seriam uma expressão de interesses negociados por diversos atores e instituições, que se organizam como rede com objetivos claros (FLEURY;OUVERNEY,2007). Para outros autores, essas redes dependem da gestão intergovernamental nas diversas escalas do exercício do poder (territoriais e regionais) e espaços colegiados do SUS, conformando redes assistenciais interfederativas (SANTOS; ANDRADE, 2011).

Entre as principais diferenças da proposta de redes forjada no sistema americano e aquelas para países com sistemas universais de saúde está a regionalização, que implica universalidade e diminuição das desigualdades (KUSCHNIR; CHORNY, 2010). Nos Estados Unidos, as redes buscam regular um sistema competitivo, fragmentado e custoso, em que a regionalização pelas redes visa compartilhar riscos financeiros e criar mecanismos rígidos de controle do acesso aos serviços (SILVA, 2011).

No Brasil, regiões e redes de saúde são organizadas pelo Estado e pelo mercado. Enquanto as redes enfatizam o caráter gerencial e logístico dos sistemas de saúde (modelos de gestão, integração econômica vertical e horizontal, regulação, continuidade do cuidado, economia de escala e escopo, coordenação técnica e governança clínica), a região tem uma perspectiva mais ampla do planejamento, sendo um espaço de negociação, coordenação e regulação técnica e política da saúde. A região abriga diversidades e desigualdades socioespaciais e envolve a negociação entre agentes e instituições, com interesses e demandas distintos e conflituosos. Nesse sentido, o planejamento regional serve para enfatizar o caráter público e universal do direito à saúde, reforçando o papel do Estado.

Através do conceito de redes de atenção, a ideia de região de saúde é atualizada pelo viés sanitário assistencial, mas, dissociado da perspectiva estritamente estatal e pública de prestação de serviços e de planejamento político-administrativo. Admite-se a participação e o protagonismo de outros agentes e instituições do mercado e da sociedade na negociação e conformação das redes de saúde.

Nesse sentido, as redes podem reconfigurar os desenhos regionais com maior frequência, pois resultam da interdependência entre fixos e fluxos materiais e imateriais hierarquizados e comandados por organizações e agentes estatais e não estatais que podem operar serviços localizados dentro e fora da região, do estado e do País. O mesmo vale para a participação da sociedade e dos profissionais de saúde, considerando que fluxos assistenciais e fluxos no mercado de trabalho nem sempre cabem dentro do recorte regional instituído.

Quando se analisam as diretrizes nacionais de regionalização e redes de atenção no SUS, identificam-se descompassos na adoção destas estratégias, muito em função das distintas perspectivas adotadas.

\section{Três fases da indução da regionalização e das redes de saúde na política brasileira}

No âmbito da política nacional de saúde, os processos de descentralização, regionalização e organização de redes assistenciais não estiveram associados desde o início da implantação do SUS. Apenas nos anos 2000, a indução da regionalização e da conformação de redes de saúde entrou na agenda, podendo ser caracterizada em três fases: fase I (2001-2005): região normativa com redes regionalizadas e hierarquizadas de serviços de saúde; fase II (2006-2010): região negociada com redes regionalizadas e integradas de atenção à saúde; fase III (2011-atual): região negociada e contratualizada com as RAS.

Essas fases se distinguem pelas concepções de região e redes que influenciaram a política de saúde brasileira e segundo as normas que definem os conceitos de regionalização e redes, 
os critérios, objetivos, desenhos, instrumentos de planejamento, financiamento e gestão e os responsáveis pela condução da organização territorial do sistema de saúde (quadro 1).

Quadro 1. Região e rede na política de saúde brasileira: diferentes fases da indução pelas normas (2001-2011)

\begin{tabular}{|c|c|c|c|}
\hline & $\begin{array}{l}\text { FASE I (2001-2005) } \\
\text { Região normativa com redes } \\
\text { regionalizadas e hierarquizadas }\end{array}$ & $\begin{array}{c}\text { FASE II (2006-2010) } \\
\text { Região negociada com redes integradas e } \\
\text { regionalizadas } \\
\end{array}$ & $\begin{array}{l}\text { FASE III (2011-atual) } \\
\text { Região negociada e contratualizada com redes de } \\
\text { atenção à saúde }\end{array}$ \\
\hline Normas & $\begin{array}{c}\text { Norma Operacional de Assistência à } \\
\text { Saúde - Noas (2001/02) }\end{array}$ & Pacto pela Saúde (Portaria 399/2006) & $\begin{array}{l}\text { Portaria } 4.279 / 10 \\
\text { Decreto } 7.508 / 11\end{array}$ \\
\hline Definições & $\begin{array}{l}\text { REGIÃO } \\
\text { Base territorial de planejamento da } \\
\text { atenção à saúde, não necessariamente } \\
\text { coincidente com a divisão } \\
\text { administrativa do estado. } \\
\text { Elementos: limite geográfico dos } \\
\text { territórios municipais envolvidos, } \\
\text { população usuária, fluxos } \\
\text { assistenciais, ações e serviços } \\
\text { de Média Complexidade (MC) e } \\
\text { responsabilidades (habilitação da } \\
\text { gestão) dos entes federativos. } \\
\text { REDES } \\
\text { Hierarquizadas e regionalizadas, sem } \\
\text { definição de um conceito específico } \\
\text { e com publicação de portarias com } \\
\text { diretrizes organizativas. }\end{array}$ & $\begin{array}{l}\text { REGIÃO } \\
\text { Recortes territoriais inseridos em } \\
\text { espaços geográficos contínuos, não } \\
\text { necessariamente coincidentes com a } \\
\text { divisão administrativa do estado. } \\
\text { Elementos: limite geográfico dos territórios } \\
\text { municipais envolvidos, população usuária, } \\
\text { fluxos assistenciais, ações e serviços } \\
\text { de Atenção Básica (AB), Média e Alta } \\
\text { Complexidade e Vigilância Sanitária (VS), } \\
\text { Colegiados de Gestão Regional. } \\
\text { REDES } \\
\text { Diversas nomenclaturas: rede regionalizada } \\
\text { e hierarquizada de ações e serviços; RAS; } \\
\text { redes regionalizadas de atenção à saúde; } \\
\text { redes regionais hierarquizadas estaduais; } \\
\text { redes funcionais; rede de cooperação entre } \\
\text { os três entes federados, sem definição de } \\
\text { um conceito específico e com publicação } \\
\text { de portarias com diretrizes organizativas. }\end{array}$ & $\begin{array}{l}\text { REGIÃO } \\
\text { Espaço geográfico contínuo constituído por } \\
\text { agrupamentos de municípios limítrofes. } \\
\text { Elementos: limite geográfico dos territórios } \\
\text { municipais envolvidos, população usuária, fluxos } \\
\text { assistenciais, RAS com rol mínimo de ações } \\
\text { e serviços (Atenção Primária à Saúde - APS, } \\
\text { Urgência e Emergência - UE, atenção psicossocial; } \\
\text { ambulatorialespecializada e hospitalar e Vigilância } \\
\text { Sanitária), Comissão Intergestores Regional (CIR). } \\
\text { REDES } \\
\text { As RAS são definidas como arranjos organizativos } \\
\text { de ações e serviços de saúde, de diferentes } \\
\text { densidades tecnológicas, que integradas por meio } \\
\text { de sistemas de apoio técnico, logístico e de gestão, } \\
\text { buscam garantir a integralidade do cuidado. }\end{array}$ \\
\hline Objetivos & $\begin{array}{l}\text { REGIÃO } \\
\text { Ampliar o acesso às ações e serviços } \\
\text { de saúde em todos os níveis de } \\
\text { atenção, por meio da conformação } \\
\text { de sistemas funcionais de saúde e } \\
\text { definindo-se um conjunto mínimo de } \\
\text { procedimentos de MC como primeiro } \\
\text { nível de referência intermunicipal a toda } \\
\text { a população no âmbito microrregional, } \\
\text { ofertados em um ou mais módulos } \\
\text { assistenciais. Descentralizar as ações } \\
\text { e serviços em saúde. Fortalecer o } \\
\text { papel dos estados no planejamento. } \\
\text { Equidade. }\end{array}$ & $\begin{array}{l}\text { REGIÃO } \\
\text { Atender às demandas das populações dos } \\
\text { municípios a elas vinculados, garantindo } \\
\text { o acesso, a equidade e a integralidade } \\
\text { do cuidado com a saúde local. Diminuir } \\
\text { as desigualdades socioespaciais de } \\
\text { universalização da saúde, superar os } \\
\text { limites do modelo de descentralização } \\
\text { municipalista da saúde e fortalecer o } \\
\text { papel dos estados no planejamento } \\
\text { e na coordenação / cooperação } \\
\text { intergovernamental. } \\
\text { Regulação dos fluxos assistenciais } \\
\text { intermunicipais e integração das ações e } \\
\text { serviços no espaço regional. }\end{array}$ & $\begin{array}{l}\text { REGIÃO } \\
\text { Compatibilizar e integrar o processo de } \\
\text { planejamento dos entes federativos. } \\
\text { Garantir segurança jurídica para as relações } \\
\text { intergovernamentais na região de saúde (Contrato } \\
\text { Organizativo da Ação Pública de Saúde - Coap). } \\
\text { Integrar a organização, o planejamento e a } \\
\text { execução de ações e serviços de saúde, por meio } \\
\text { da conformação das RAS. Associar planejamento } \\
\text { e orçamento: região como referência para } \\
\text { transferência de recursos entre os entes federados. } \\
\text { Diminuir as desigualdades socioespaciais de } \\
\text { universalização da saúde, superar os limites do } \\
\text { modelo de descentralização municipalista da saúde } \\
\text { e fortalecer o papel dos estados no planejamento e } \\
\text { na coordenação / cooperação intergovernamental. } \\
\text { Governançadas redes. Metas e resultados. } \\
\text { REDES } \\
\text { O objetivo das RAS é promover a integração } \\
\text { sistêmica, de ações e serviços de saúde com } \\
\text { provisão de atenção contínua, integral, de qualidade, } \\
\text { responsável e humanizada, bem como incrementar } \\
\text { o desempenho do Sistema, em termos de acesso, } \\
\text { equidade, eficácia clínica e sanitária; e eficiência } \\
\text { econômica. }\end{array}$ \\
\hline
\end{tabular}


Quadro 1. (cont.)

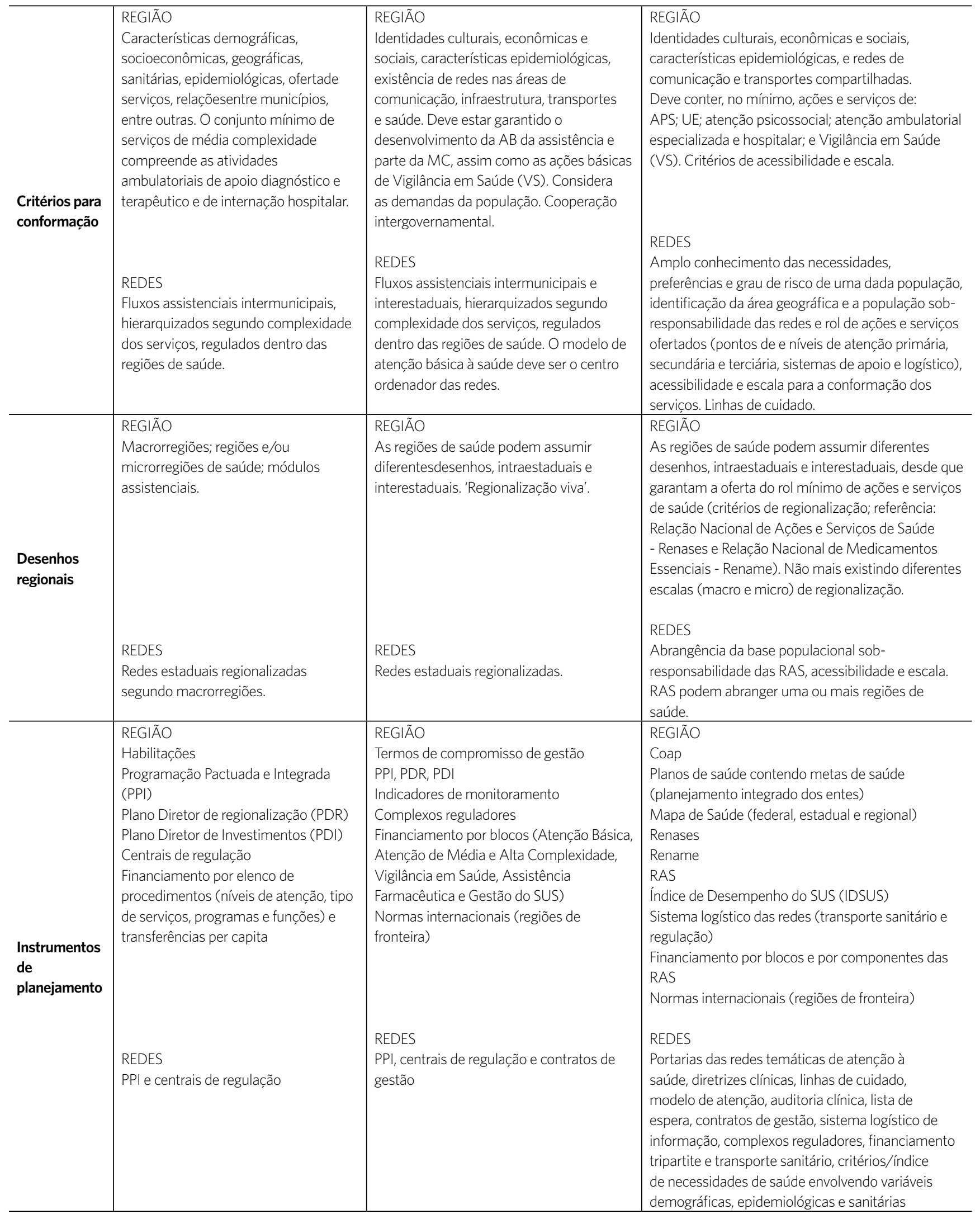




\begin{tabular}{|c|c|c|c|}
\hline \multicolumn{4}{|l|}{ Quadro 1. (cont.) } \\
\hline Responsáveis & $\begin{array}{l}\text { REGIÃO } \\
\text { Secretarias Estaduais de Saúde } \\
\text { Comissão Intergestores Bipartite (CIB) } \\
\text { REDES } \\
\text { Secretarias Estaduais de Saúde } \\
\text { Secretarias Municipais de Saúde } \\
\text { CIB }\end{array}$ & $\begin{array}{l}\text { REGIÃO } \\
\text { Secretarias Estaduais de Saúde } \\
\text { Secretarias Municipais de Saúde } \\
\text { Colegiados de Gestão Regional } \\
\text { CIB } \\
\text { Comissão Intergestores Tripartite (CIT) } \\
\text { (no caso de regiões nas áreas de fronteira } \\
\text { internacional) } \\
\text { REDES } \\
\text { Secretarias Estaduais de Saúde } \\
\text { Secretarias Municipais de Saúde } \\
\text { Colegiados de Gestão Regional } \\
\text { CIB }\end{array}$ & $\begin{array}{l}\text { REGIÃO } \\
\text { Secretarias Estaduais de Saúde } \\
\text { Secretarias Municipais de Saúde } \\
\text { CIT (no caso de regiões nas áreas de fronteira } \\
\text { internacional; na discussão das diretrizes de } \\
\text { regionalização) } \\
\text { CIB } \\
\text { Comissão Intergestores Regional (CIR) } \\
\text { REDES } \\
\text { Governança das redes: Secretarias Estaduais de } \\
\text { Saúde, Secretarias Municipais de Saúde, Comissões } \\
\text { Intergestores Regionais e Bipartite, reguladores, } \\
\text { financiadores e prestadores públicos e privados, } \\
\text { Comitê Gestor das Redes. }\end{array}$ \\
\hline
\end{tabular}

Fonte: Elaboração própria com base nas normas nacionais de regionalização e RAS da política nacional de saúde brasileira.

A primeira fase, que teve início com a Noas (2001/02), dialoga com a proposta de Dawson das redes assistenciais regionalizadas e hierarquizadas, dentro da lógica de um sistema de saúde funcional e resolutivo. $\mathrm{O}$ grande objetivo da regionalização era ampliar o acesso ao SUS, retomando sua coerência sistêmica, organizando fluxos intermunicipais pouco regulados, integrados e negociados, promovendo o papel dos estados no planejamento e coordenação das redes intermunicipais. Contudo, não foi elaborado um conceito específico para as redes assistenciais que pudesse subsidiar o planejamento e as negociações, apenas portarias com diretrizes organizativas para redes estaduais. As regras da regionalização, quando confrontadas com a realidade diversa e desigual do território brasileiro, foram consideradas rígidas e pouco efetivas, caracterizando regiões normativas (BRASIL, 2004). A exemplo da dificuldade de implantação das Programações Pactuadas Integradas.

A segunda fase, que se iniciou com o Pacto pela Saúde (2006), representa uma transição das concepções de região e redes na política de saúde nacional. $\mathrm{O}$ uso de diversas nomenclaturas para redes, com menção às RAS, aponta a influência da proposta da OMS de sistemas integrados de saúde na política brasileira. As redes são compreendidas como integradas e regionalizadas, sem um conceito definido, pautada por diretrizes organizativas, destacando as referentes aos Serviços de Urgência e Emergência. Contudo, a questão mais importante é o uso do termo rede de cooperação entre os três entes federados ante a necessidade de maior coordenação e cooperação intergovernamental na gestão do SUS. São criados os Colegiados de Gestão Regionais (CGR), posteriormente denominados Comissões Intergestores Regionais (CIR), e flexibilizados os critérios para a conformação das regiões de saúde, dando oportunidade para recortes mais variados e adequados às realidades locais. Tratou-se de um processo de regionalização baseado na negociação, envolvendo todos os gestores, em um contexto territorial complexo (divisão tripartite do poder e diversidade de situações sanitárias existentes). Contudo, os instrumentos de planejamento continuaram os mesmos da fase anterior, limitando a negociação e a coordenação política.

Nessa fase, as regionalizações se diferenciaram muito quanto à institucionalidade, governança e objetivos propostos no âmbito dos estados e associaram-se, em grande medida, aos objetivos de redução das desigualdades regionais, amparados pela expansão dos investimentos públicos federal e estadual (VIANA; LIMA, 2011). Os consórcios intermunicipais e a regionalização negociada se combinaram de maneira a respeitar o desenho de alguns 
consórcios e, também, redefinir as responsabilidades dos governos (SCATENA ET AL., 2014). Entretanto, esse processo instituiu regiões muito desiguais do ponto de vista da oferta de serviços, da população atendida e da capacidade técnica, financeira e decisória de organização de redes assistenciais, muitas vezes sem ganhos de escala e escopo.

Na fase III, a publicação da Portaria 4.279/2010 e do Decreto 7.508/2011 consolidou a nova perspectiva das RAS na política nacional. Contribuíram para isso: a criação da Diretoria de Articulação de Redes de Atenção à Saúde (Daras/SAS/MS), em 2007, o Programa dos Territórios Integrados de Atenção à Saúde (Teias) e a elaboração de um documento base sobre RAS para o País. Experiências estaduais (CE, ES, MG) e municipais (Curitiba, Rio de Janeiro) de conformação de redes de atenção, ocorridas desde o final da década de 1990, também subsidiaram a política nacional. O Banco Mundial propôs e financiou a implantação de redes integradas no País, a exemplo do Projeto QualiSUS-Rede. Trata-se de um movimento de demanda por mais recursos financeiros para o setor saúde alinhados às redes de atenção.

Do ponto de vista do planejamento regional do SUS, destaca-se o papel da Secretaria de Gestão Estratégica e Participativa (Segep/MS) e a atuação do Consórcio da Catalunha na equipe ministerial sob a forte influência da experiência Catalã, adaptada ao Brasil no estado do Sergipe. O Decreto $7.508 / 11$ trouxe mudanças significativas na concepção, nos objetivos e instrumentos do planejamento regional. Por um lado, buscou garantir flexibilidade e ganhos de escala e escopo no desenho regional e, por outro, buscou responsabilizar de forma clara e objetiva as três esferas de governo pelo planejamento, gestão e investimentos nas regiões de saúde. Trata-se de conformar regiões negociadas e contratualizadas.

Apesar do Decreto 7.508/11 trazer novas perspectivas de região e de redes de atenção, a elaboração e institucionalização dessas duas estratégias caminharam paralelamente e não se coadunam. Entre 2011 e 2013, as portarias e projetos para implementação das redes temáticas de atenção à saúde trouxeram pouca ou nenhuma relação com os novos instrumentos da regionalização (AlbuQuerque, 2013). Mesmo o Projeto QualiSUS-Rede selecionou regiões metropolitanas e outros recortes priorizados na Política Nacional de Desenvolvimento Regional, sem relação com regiões de saúde. Apenas dois estados assinaram os Coaps nas suas regiões de saúde (MT, CE).

A proposta das RAS redefine a região como 'sanitária', baseada em sua população-alvo e abrangência espacial que extrapola o recorte das regiões de saúde. Levando em conta que o repasse de recurso novo está vinculado às redes temáticas, sua implantação tende a reconfigurar as regiões estabelecidas (MENDES, 2014). Ao mesmo tempo, sugere uma redistribuição do poder entre instituições públicas e privadas e entre as três esferas de governo, com tendências de centralização de certas funções nos estados e no nível federal (VARGAS ET AL., 2014). É possível que novos desenhos sejam estabelecidos, regiões mais dinâmicas e flexíveis, diferentemente daqueles formalmente instituídos como região de saúde.

\section{Conclusão}

A indução da regionalização e a conformação de redes de saúde ocorreram de maneira descompassada, orientadas por diferentes concepções teóricas e políticas e interesses nacionais e internacionais. A perspectiva das RAS é a face mais recente do alinhamento da política brasileira com diretrizes internacionais de reforma dos sistemas universais.

A proposta das redes de atenção vem se tornando consenso na política nacional, que também se explica porque a rede supre a necessidade de um novo modelo de organização territorial do SUS, provocando a revisão da perspectiva regional do planejamento da saúde. 
É limitada a concepção de região de saúde seja como resultante de dinâmicas constituídas apenas em sua escala espacial, seja como ferramenta exclusiva à ação dos atores estatais.

Modelos de organização territorial do sistema de saúde e suas combinações, em constante disputa no âmbito da federação, são condicionados por dinâmicas espaciais e relações entre Estado, mercado e sociedade na condução da política e das redes de saúde. Há mudanças tanto no modo como se realiza a política (multinível) quanto na

\section{Referências}

ALBUQUERQUE, M. V. O enfoque regional na politica de saúde brasileira (2001-2011): diretrizes nacionais e o processo de regionalização nos estados brasileiros. 2013. 280 f. Tese (Mestrado em Ciências) - Faculdade de Medicina, Universidade de São Paulo, 2013.

BRASIL. Ministério da Saúde. A regionalização da saúde. Brasília, DF, jun. 2004. (Versão preliminar para discussão interna).

CASTILLO, R. Região competitiva e logística: expressões geográficas da produção e da circulação no período atual. In: SEMINÁRIO INTERNACIONAL SOBRE DESENVOLVIMENTO REGIONAL. 4., 2008, Santa Cruz do Sul Anais... Santa Cruz do Sul: Universidade de Santa Cruz, 2008.

FLEURY, S.; OUVERNEY, A. M. Gestão de redes: $a$ estratégia de regionalização da política de saúde. Rio de Janeiro: FGV, 2007.

HARTZ, Z. M. A.; CONTANDRIOPOULOS, A. P. Integralidade da atenção e integração de serviços de saúde: desafios para avaliar a implantação de um "sistema sem muros”. Cad. Saúde Pública, Rio de Janeiro, v. 20, supl. 2, p. S331-S336, 2004.

IBAÑEZ, N. et al. O Pacto pela Saúde e a gestão regional em São Paulo: estudos de caso do mix público privado. In: VIANA, A .L. d'Á; ELIAS, P. E. M.; IBAÑEZ, N. (Org.). Saúde, desenvolvimento e território. São Paulo: Hucitec, 2009. forma da ação coletiva, permeada por atores públicos e privados organizados em redes de atenção. Potencializar a negociação, a regulação e a coordenação de um sistema de saúde implica redefinir os papéis dos agentes operadores do sistema e da política, em um ambiente de autonomia e participação, por meio de novas tecnologias de cooperação que atravessam técnicas de gestão e organizativas dos fatores de produção em saúde, capazes de melhorar a eficiência dos investimentos e a eficácia dos serviços.

KUSCHNIR, R.; CHORNY, A. H. Redes de Atenção à Saúde: contextualizando o debate. Ciênc. Saúde colet., Rio de Janeiro, v. 15, n. 5, p. 2307-2316, ago. 2010.

MELLO, G. A.; IBANEZ, N.; VIANA, A. L. d'Á. Um olhar histórico sobre a questão regional e os serviços básicos de saúde no estado de São Paulo. Saúde Soc., São Paulo, v. 20, n. 4, p. 853-866, out./dez. 2011.

MENDES, E. V. Comentários sobre as Redes de Atenção à Saúde no SUS. Divulgação em Saúde para Debate, Rio de Janeiro, n. 52, p. 38-49, out. 2014. As Redes de Atenção à Saúde. Ciênc. Saúde colet., Rio de Janeiro, v. 15, n. 5, p. 2297-2305, 2010.

ORGANIZACION PANAMERICANA DE LA SALUD (OPAS). Redes integradas de servicios de salud: Conceptos, opciones de política y hoja de ruta para su implementación en las Américas. Washington DC: Organizacion Panamericana de La Salud, 2010.

SANTOS, L.; ANDRADE, L. O. M. Redes interfederativas de saúde: um desafio para o SUS nos seus vinte anos. Ciênc. saúde colet., Rio de Janeiro, v. 16, n. 3, p. 1671-1680, mar. 2011.

SANTOS, M.; SILVEIRA, M. L. O Brasil: território e sociedade no início do século XXI. Rio de Janeiro: Record, 2001.

SCATENA, J. H. G. et al. (Org.). Regiões de saúde: diversidade e processo de regionalização em Mato Grosso. São Paulo: Hucitec Editora, 2014, p. 426-450. 
SILVA, S. F. Organização de redes regionalizadas e integradas de atenção à saúde: desafios do Sistema Único de Saúde (Brasil). Ciênc. saúde colet., Rio de Janeiro, v. 16, n. 6, p. 2753-2762, jun. 2011.

SILVEIRA, M. L. Região e globalização: pensando um esquema de análise. REDES, Santa Cruz do Sul, v. 15, n. 1, p. 74-88, 2010.

VARGAS, I. et al. Regional-based integrated healthcare network policy in Brazil: from formulation to practice. Health Policy Plan, Oxford, v. 30, n. 6, jun. 2014.
VIANA, A. L. d'Á.; LIMA, L. D. (Org.). Regionalização e relações federativas na política de saúde do Brasil. Rio de Janeiro: Contra Capa, 2011.

WORLD HEALTH ORGANIZATION (WHO). Towards unity for health: challenges and opportunities for partnership in health development. Geneva: WHO, 2000.

Recebido para publicação em maio de 2015 Versão final em setembro de 2015

Conflito de interesses: inexistente Suporte financeiro: não houve 